Masuma H. Mammadova', Huseyn A.Gasimov ${ }^{2}$

DOI: 10.25045/jpit.v08.i2.06

Institute of Information Technology of ANAS, Baku, Azerbaijan

${ }^{1}$ masuma.huseyn@iit.ab.az; ${ }^{2}$ hqasimov@gmail.com

\title{
E-UNIVERSITY: CONCEPTUAL, TECHNOLOGICAL AND ARCHITECTURAL APPROACHES
}

In the context of the modern educational paradigm "lifelong learning", we consider the global processes taking place in the world. The paper explores conceptual approaches to the design of electronic universities. It presents a comparative analysis of the characteristics of distance technologies and the models of electronic education through the prism of the evolution of ICT. Taking into account the educational environments of different countries, the paper provides appropriate architectural solutions for distance education systems. Furthermore, the status of e-education in Azerbaijan is provided. The article proposes a structural diagram of the electronic university that is consistent with the specifics of the educational environment in Azerbaijan.

Keywords: lifelong learning, distance education, conceptual approaches, electronic universities models, technological characteristics, architectural solutions.

\section{Introduction}

The formation of a knowledge-based innovation economy is a key indicator of the modern development phase of the information society. The modernization of education in the globalizing world aims at ensuring the adequate response to the challenges for the satisfaction of social needs and responding to all requests of each citizen and the society. The improvement of the quality of education envisages the renewal of its content, enhancing access to education, transferring the education process from traditional audiences to virtual audiences, enhancing the independent work of learners and optimizing the teaching process. In order to form a new concept of education, it is crucial to make global changes in the education system as a whole and, first of all, develop a so-called electronic-university.

\section{A new approach to the organization of education in the context of knowledge society}

One of the key features characterizing the information society is a continuing education. The goal of the continuous education is to offer and provide new opportunities to the people of different ages to adapt to the transformations emerging in the society, economy, technology, professional activities and so forth. Continuous education involves multiple qualification courses in various specializations or retraining for any person throughout his or her life. A new concept of education developed by UNESCO specifies that the principles of "lifelong learning", "education for all" and "boundless education" are forming the basis for the knowledge society, in which the Internet is a locomotive for this process [1]. The policy of lifelong learning is aimed at ensuring the transition between different education and training systems. It is based on the possibility of continuing the learning process of a human not only within a limited formal education, but also in the non-formal fields, including the public, scientific, cultural, and other spheres of life. The lifelong learning process persists throughout the life and proves itself in every field [2].

The most important factor influencing the development of education at the moment is its globalization. This factor reflects the existence of the integration processes in the modern world and intensive interaction between the countries in various spheres of public life. The ongoing tendencies identify the key trends in the development of a new education system and envisage a broader application of ICT in the educational process. Just the technological and infrastructural basis of the ICT enables the realization of the electronic (distance, remote, online, or virtual) education, which is one of the most important advantages of the new educational system.

Recently, in addition to the term "distance learning", the term "e-education" and "e-university" has been used in the literature. Some researchers believe that the process of integration of the ICT-based traditional and distant learning is mostly referred to the term "e-learning". Another group of experts also 
define the term "e-learning" as a new generation of distance learning and use "electronic learning" and "distance learning" as inseparable definitions. In the post-Soviet world, the concept of "e-education" is often identified with the term "distance education" [3, 4]. In the presented article, the terms, such as "eeducation", "distance learning", "distance education" and "online education", are used synonymously.

E-learning provides learners with the opportunity to obtain the necessary knowledge using independent information resources. E-education plays a strategic role in addressing the following issues for the development of national education systems: 1) modernization and development of the national education systems; (2) providing everybody with the access to quality education (without age limit); 3) establishing the links between education and labor market; 4) providing lifelong learning accessibility in $24 \times 7 \times 365$ mode for different categories of people, taking into account their interests and needs; 5) supporting opportunities for independent learning; 6) reducing economic and geographical inequality, ensuring access to the best educational content for residents with low-income and living in remote regions; 7) prompt training the specialists for modern work places; 8) involving the people with disabilities into the educational process and so on. [5].

\section{Conceptual approaches to the projection of e-universities}

The notion "e-university" refers to the educational structure that implements and develops e-learning in this or that country and involves the emergence of the new forms of electronic (distance, online, virtual)education. It is no coincidence that, currently, the discussion of the opportunities and roles of e-universities in solving the organizational development problems of higher education is considered to be one of the main topics [6].

In the literature, the term "digital" is rather prevalent compared to "electronic", "online" and "virtual" university terms. At present, the formation of digital universities has expanded worldwide $[7,8]$.

Increasingly using ICT opportunities, the digital universities are introducing new trajectories of the knowledge accessibility, affecting educational policies of universities, and moreover, becoming a leading tool in their transformation. The needs for the digital universities in recent years and the widespread e-learning are linked to the following factors: 1) emergence and growth of a new generation of young people (students) who require the introduction of completely different models of higher education; 2) economic factor related to the fear of losing students, 3) requirements aimed at improving the quality of education; and 4) need to increase the efficiency of the university performance. The provision of these four factors within the e-university project will enable the universities to adapt to the new market economy conditions, and will eliminate the risk of their closure and increase their budgets.

Thus, developing the e-university is not just a good idea, but also a necessity. The delay of the process of the e-university establishment can lead to negative outcomes $[9,10]$.

The analysis of the development of university education throughout the world shows that new university concepts are being shaped under the influence of ICT and market relations. These conceptual approaches and models combine several different institutional (organizationalmanagerial) forms of the traditional and distant education. Numerous scientific works on the euniversity are available now [6-13], though, a perfect and universal e-university model has not been formed in the world yet. The idea of the e-university emerged in the mid-1980s. During this period, many US colleges and universities were attempting to apply telecommunication technologies and computer networks to remote (distant) education for older students.

The concepts of e-university and distance learning are interconnected, contributing to the emergence of the distance learning, independent learning, overseas teaching and open universities. Multimedia tools, such as the Internet, Skype, e-mail are widely used in the delivery of educational materials to the students of such educational institutions. As in real education, regardless of the teaching mechanisms and interface tools, the main issue is to provide quality content and materials to the learners. Without quality content, the education loses sense both in physical and e-university. 
In many leading countries, e-university is now recognized as a higher education institution that regulates and delivers higher education of the learner in terms of being at a distance from the tutor. Currently, there are many e-university models in the world. These e-universities can be divided into three groups according to the overall organizational and managerial structure. These institutional forms include: 1) on-off-campus model with remote education departments in the traditional and open universities; 2) off-campus model; 3) consortium of universities or a consortium based e-university model; 4) tele-universities, and 5) virtual universities [11-22].

In the e-universities based on the on-off-campus model, in addition to the traditional teaching of the subjects, the distance education is also electronically provided. In most cases, these universities conduct final exams in a unified form for the students of both the full-time and distant departments. The introduction and development of distant education in traditional universities is characterized by a number of advantages. Thus, the distance education in the classical universities: 1) enlarges the spectrum of the services provided; 2) increases the competitiveness against the other educational providers (across the country or abroad) which develop and offer non-traditional training courses; 3 ) in many cases, promotes commercial opportunities based on the principle of self-financing. However, the e-university can also be implemented as a virtual and noncommercial equivalent of a classic university.

Recently emerged and actively used the "Blended Learning" term demonstrates the replacement of the traditional teaching forms (face-to-face, print materials, etc.) by the electronic technology [23].

Distant and open-type institutional education model, in contrast to the first model, only produces e-learning, and these universities do not have traditional campuses. Such educational institutions follow the individual education policies and implement curriculums through the distance learning technologies and adopt individual education degrees for the students. Characteristic factors for the formation and development of distant and open universities may include part-time education experience and infrastructure, ICT-based new educational models and the network of centers providing them, the new economic and organizational mechanisms in line with the innovative technological basis of the educational process. The institutions delivering the distant education have been widely spread worldwide. These types of educational institutions differ according to some aspects. The scope of these enterprises depends largely on the conditions set by this or that state.

The Consortium of Universities (lat. Consortium- partnership and co-operation) is a relatively new and actively emerging institutional model of the university education in recent years. Consortium-based university education model combines and co-ordinates the performance of several universities through advanced ICT. With the help of the Consortium of Universities, each member university has the opportunity to use the resources and equipment of others to provide the quality education services. The essence of such an institutional model is the opportunity of remotely obtaining the degree. Furthermore, certification of the universities are included in the consortium.

Tele-university is a new institutional form of university education based on the combination of the resources of the traditional universities. Nonetheless, this unity is more powerful than the university consortium. Tele-university offers joint work on an integrated curriculum of a number of independent universities. Tele-university independently prepares and presents courses, degrees, diplomas and certificates, using professorial-teaching staff, lecture halls and other resources from the traditional universities.

Virtual universities are new types of educational institutions that fully realize potential opportunities of ICT, offering educational programs with the application of only e-learning and distance learning technologies. Virtual universities do not have buildings, student dormitories, campus, cabinets for administrative staff, and lecture halls. It consists of collaborators, co-workers, trainers, educators, technicians, employed and interactively educated learners who live in remote distances, often beyond the 
national boundaries using modern ICT. This model has not been fully implemented yet. It faces serious difficulties, particularly the problem of virtual university accreditation, in other words, gaining public trust, obtaining the right to provide the diplomas and certificates and appropriate degrees.

\section{Electronic education technologies}

As mentioned above, electronic universities are educational institutions that are realizing and stimulating the formation and development of the electronic education. The basis of the electronic (distance) education is technology, which primarily provides the interaction between learner and 8educator, regardless of location and time. The development of ICT will lead to the emergence of the new forms of e-learning, which, in turn, has a direct impact on the organizational development of the higher education and the solution of e-university architecture. Therefore, the problem of developing the e-university concept is directly related to the study of the development processes of the types, technologies and models of e-learning. The international practice shows that e-learning systems ensure that the learning process is adapted to the individual characteristics of the learner. They also release teachers from a number of routine and laborious operations as teaching materials and knowledge testing, enabling the development of objective methods of knowledge verification. Additionally, these systems facilitate obtaining the educational and methodological experience. The educational process is carried through the usage of wide range electronic technologies (PCs, television and satellite technologies, radio, CDs, mobile technologies, WWW-technologies, etc.).

From the point of view of the communication and style of the education, there are two types of e-learning technologies - synchronous and asynchronous.

The synchronous e-learning involves the real-time interaction of an educator (tutor) and learner. The tutor can evaluate the student's response, identify the needs, react to them (to answer his/her questions, choose the appropriate temp, follow the learner's involvement into the process, etc.). The online synchronous interaction of the learner and the educator is realized through the use of the technologies such as dual chats, video or audio conferencing.

During the asynchronous education, a learner is responsible for the learning process as the time and mode of which is wholly chosen by the learner. Asynchronous education is linked to "e-learning" on demand. The asynchronous e-learning category includes traditional e-learning courses that are currently used in many universities around the world. Regardless of how the course is delivered to the learners (either through the disk or through the teaching management system), the communication with a teacher is interrupted depending on the time [5, 24].

Undoubtedly, the Internet is a global platform for knowledge sharing between the learner and the educator within the framework of the leading infrastructure, information storage and education in various e-learning institutions.

The rapid growth of the global network and the expansion of the Internet services have proven the need for it. This, in turn, stimulated the development of web-oriented concepts and technologies that had led to the development of Web versions (Web 1.0, Web 2.0, Web 3.0) used in electronic education. The analysis of the evolution of Web technology that directly impacts on the interaction of the users with the resources enables us to describe and compare the models of eEducation 1.0, e- Education 2.0 and e- Education 3.0 [25, 26].

Web 1.0 (1990-2000) is the first step in the conceptual evolution of the global network. This stage, also referred as static, is characterized by the fact that the content was created by a small number of active network members (teachers, large education centers and companies) while most users were only a part of the content; the information was not dynamic, only webmaster could change the websites.

As the first generation of the Internet, Education Model 1.0 is a one-sided process that can be described as a traditional e-learning by using a personal computer. The learners act as the passive consumers of information sent by the teachers. The use of shared materials, projectors, interactive boards, video and Internet accessibility in the traditional education do not change the educational models. 
The emergence of Web 2.0 (2001-2010) was due to the desire of most users to be involved in the content generation. Transition from Web 1.0 to Web 2.0 has resulted in the emergence of the services that provided the broadband Internet and allowed the users to create their own Internet content and to discuss them with the readers. Blogs, social networks, file sharing networks, AJAX, XML, RSS and other technologies are the services that have been developed in the Web 2.0 framework and entered almost everyone's live.

Web 2.0 is a dynamic, flexible, and adaptive space enough that allows any user to generate and share information on the Internet [27]. The Education Model 2.0 is characterized by the use of Web 2.0-related technologies used for teaching and learning. Blogs, wiki-pages, and other social media tools are widely welcomed by modern students and used in e-learning. The use of Web 2.0 tools in Education Model 2.0 also creates new opportunities for the learners(students)to obtain educational contents, as well as to generate them. Later, the teaching trajectory control function often goes from the teacher to the learner [28].

The Semantic and the Web 3.0 conception, based on semantic data processing, was offered by a number of leading WWW corporations (Google, IBM, Oracle and others) as the key development trend of the Internet during the next 10 years (2011-2020). The Semantic Web is designed to address the most pressing problem of the development of the Internets, i.e., the search for the significant data and its extraction out of the information abundance. The concept of Web 3.0, as opposed to the previous generation Web 2.0, involves the use of advanced technologies such as semantic networks, 3D virtualization, intelligent data filtering, 3D touch user interface, cloud computing and intelligent agents $[23,29]$. The Education Model 3.0 should exceed the boundaries of the traditional educational institutions having more self-organized learning capabilities. In other words, the new educational model should be individual-oriented (personalized) based on the capabilities of modern information technology. The Education Model 3.0requires the following essential components: 1) cloud computing technologies that significantly increase data storage capacity and their processing facilities; 2) mobile technologies that provide access to any educational resources anywhere and anytime using mobile devices; 3 ) controlled content filtering and directing to multifunctional services; 4) 3D technology that enhances the accuracy of the teaching process as a whole.

The further development of the educational models is associated with the creation of a smart educational environment and, accordingly, the Smart Education [30]. Thus, the universities that are the leading players in the new knowledge market must be modified and adapted to the realities and needs of the information society in which the educators are not only the teachers, but also anyone with the necessary competencies of the Internet. Due to the development of information technology, the educational paradigm "student - teacher" is gradually transformed into the paradigm "student paradigm", which enables a new stage in the development of e-learning, that is the transition to Smart Education. The smart e-learning system is based on the intellectual technology that provides access to the virtual learning environments through the smart devices. It provides flexible educational opportunities to the students anywhere and anytime based on free access to the content all over the world (Education module 3.0). Education 3.0is based on a personalized approach that enables the development of individual multidisciplinary (as well as interdisciplinary) education programs.

Another aspect of the development of intelligent online education systems is multi-agent technologies. Within the framework of the multi-agent approach, the distance learning system is built on a set of intelligent agents, each of which has a semantic description of the subject field, tracking the personal data, exchanging with the information with other agents for a compromise, and other qualities. An intellectual agent is soft ware operating within the interests of reaching the goals set by the learning environment $[31,32]$.

As a rule, the electronic education system incorporates the tools for teaching, testing, practical exercises, and the user's (learner's) distance communication with the educator. The realization of the agent programs that help the learners and teachers will assist to develop the personalized user interface and ultimately to enhance the quality and effectiveness of teaching and learning activities. 


\section{Architecture of distance learning systems in e-universities}

Currently, different countries are experiencing the unique structures of Distance Learning Systems (DLS), which are the basis of educational activities according to different e-learning models [33]. Let's take a brief look at some of them.

Tracey M. and Richey R. describe the structural scheme of DLS used in e-universities in their works [14] devoted to the development of the distance education as illustrated in Figure 1.

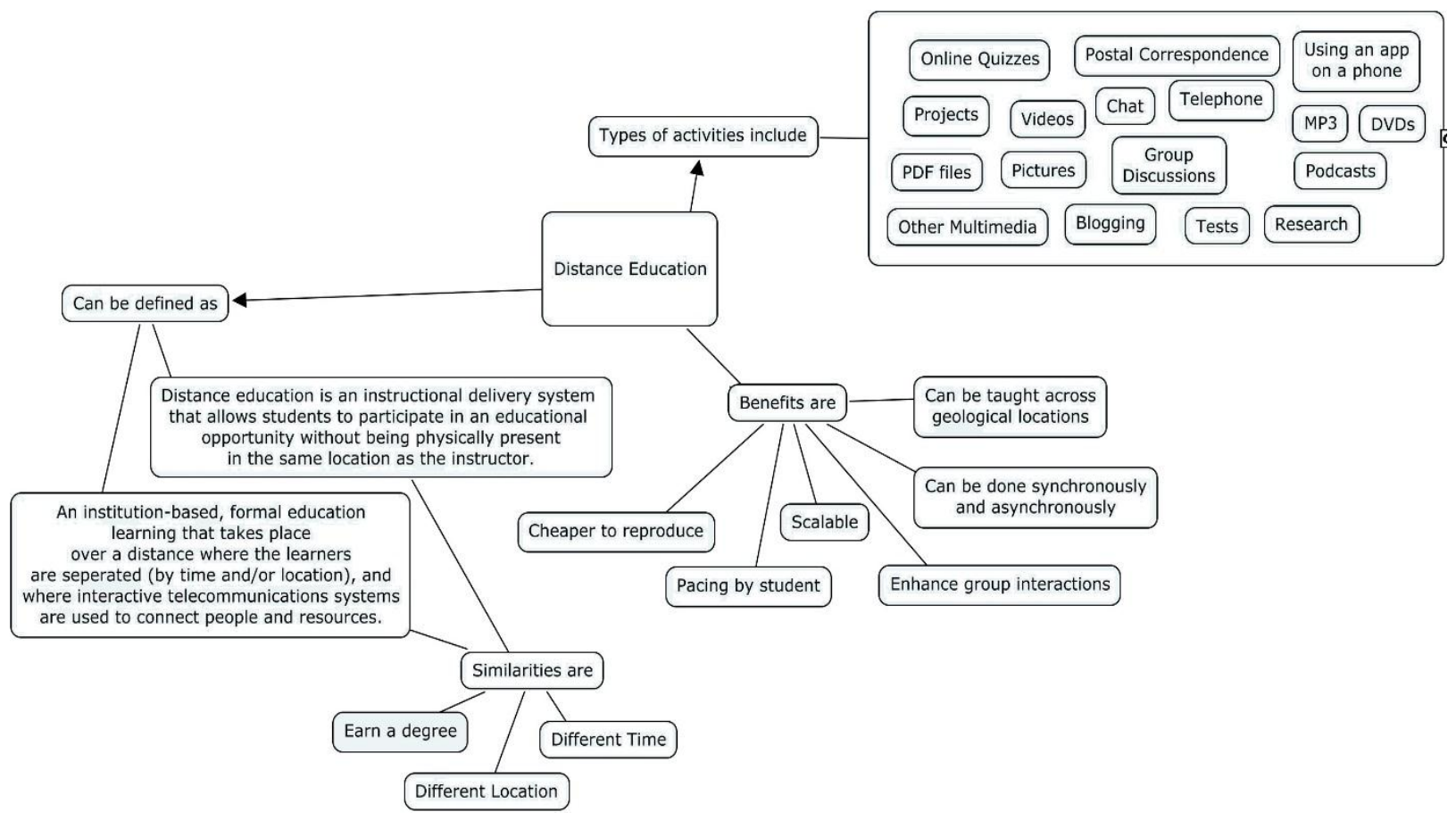

Figure 1. The structural scheme of DLS

As can be seen from the Figure 2, the distant education system supporting the hybrid modeled e-university can provide synchronous and asynchronous e-learning services to both students and different categories of citizens in line with their lifestyle and activity forms.

Jennifer Tricoli [34] describes the structural scheme of the e-university as below, in the case if the educational tools existing and intended to be use dat the education facilities will be applied with the online educational tools [Figure 2]. The scheme also shows that even in the developed countries, they haven't fully transited to the virtual education, or a complete virtual university model has not been implemented yet. 


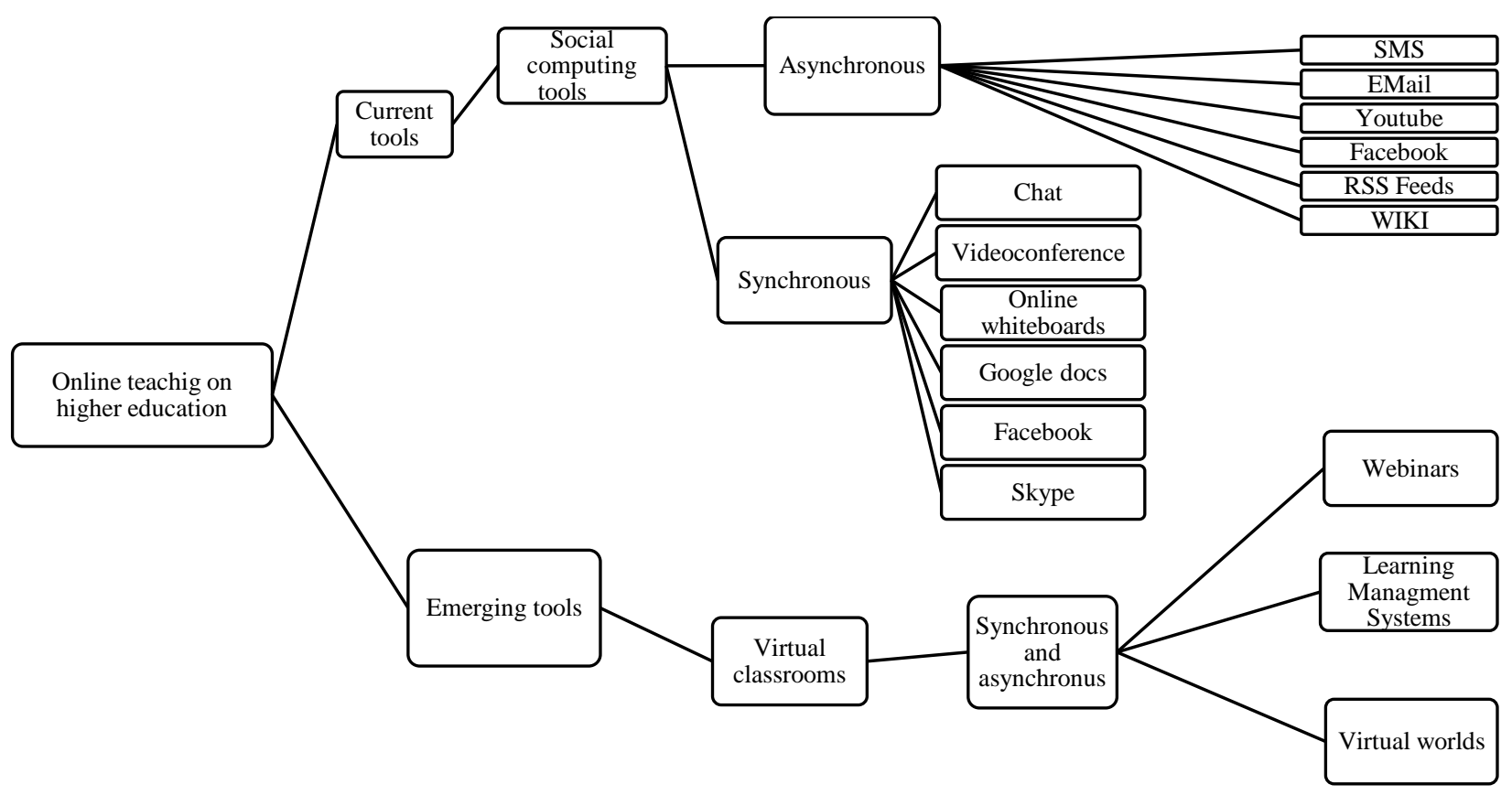

Figure 2. Structural scheme of online education at universities

[35] The main focus of the structural scheme of the e-university is the digitization of subject learning (Figure 3). At the same time, emerging e-university model is based on Web 2.0 technology.

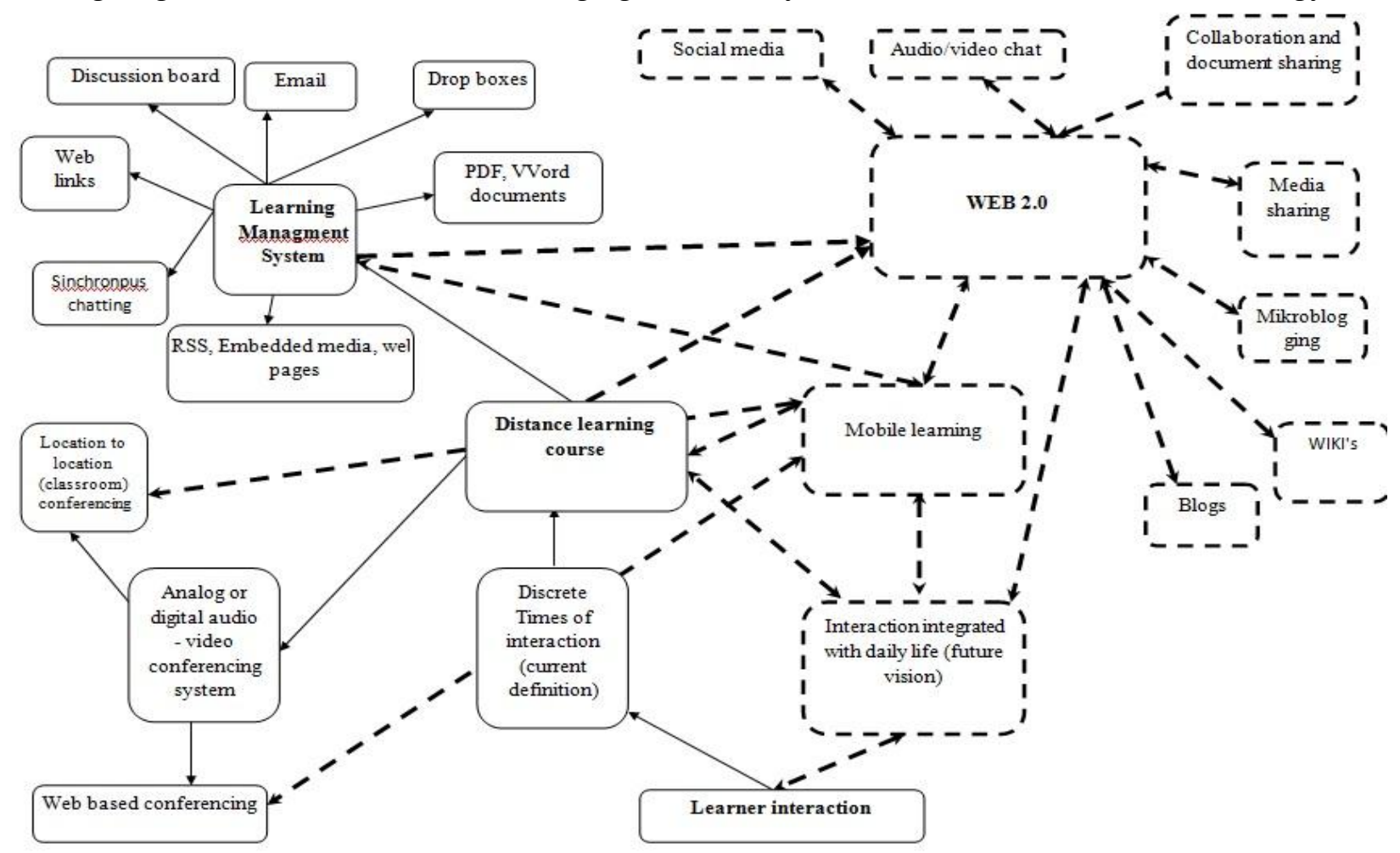

Figure 3. The Web 2.0-based structural model of e-university

As a result of the research, a more interesting e-learning model emerges, which is introduced in the People's Republic of China. This e-university is mostly compatible with a consortium model. The educational process is performed via the satellite. The structural scheme of the model is given below (Figure 4). 


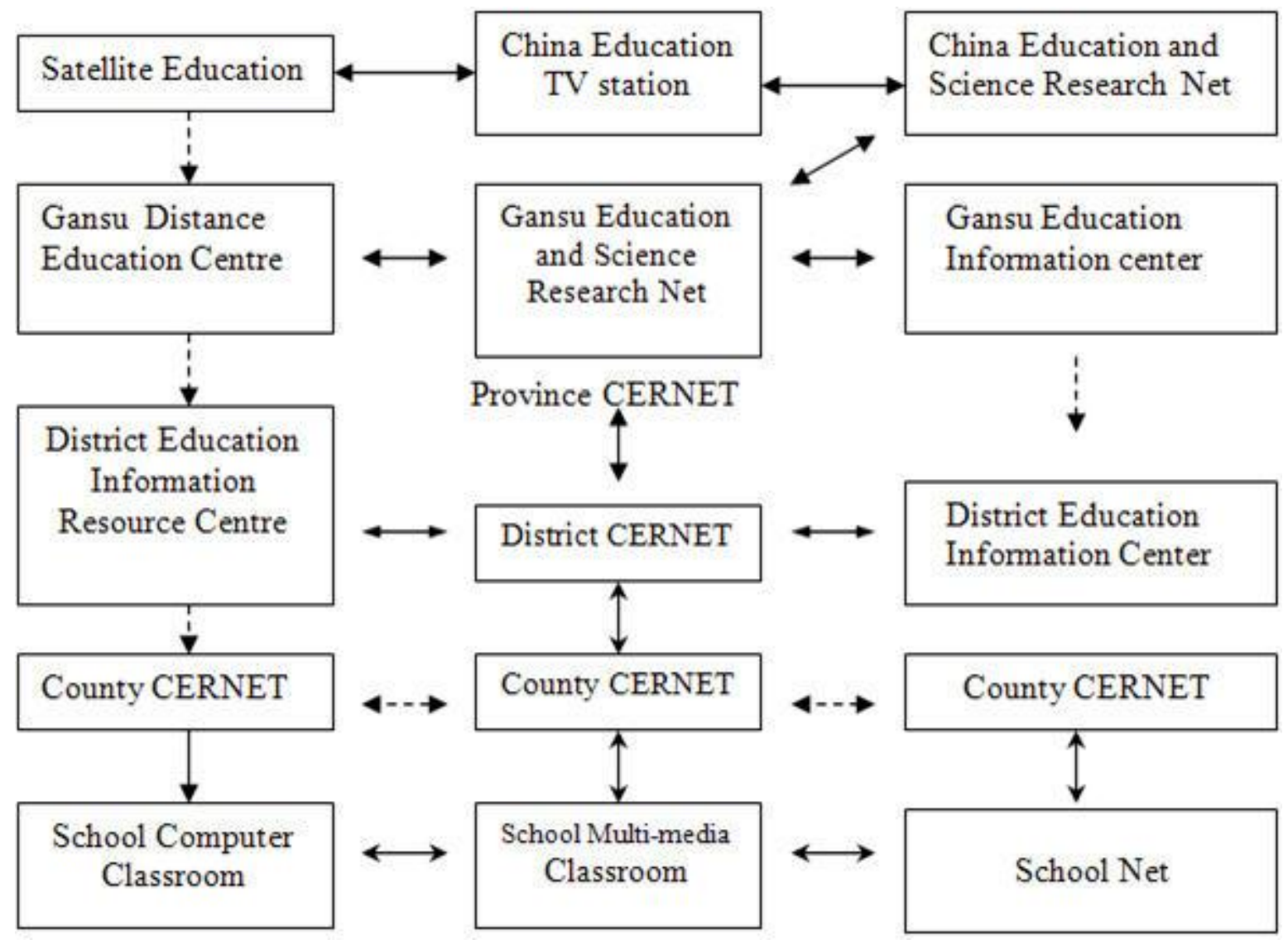

Figure 4. The e-university model used in the People's Republic of China [36]

The international experience shows that there are different types of e-university models in the world. These models depend on the goals set by the university for human resources, education legislation of the country, the attitude of the population towards the education, and so on. In spite of some non-invariant principles, all of this allows to conclude that e-university concepts cannot be universal. At present, no country in the world has a complete e-university. All universities offer some e-services.

\section{The need for introducing e-education in Azerbaijan}

As in the leading countries, the distance learning is considered to be one of the topical issues of the day in Azerbaijan. This urgency shows itself in many factors. According to the statistical data, the number of the population with secondary education in Azerbaijan is at a very high level compared to other countries. Thus, $99.5 \%$ of the population in the country is considered to be functionally competent [37]. According to the current education law of the Republic of Azerbaijan, the people with limited health can also receive higher education at home, with the help of elementary and correspondent forms of education. Even in the rural districts located far from the center, the special schools are organized for the children with limited mobility and they are taught online.

Despite these positive indicators, the situation, in terms of the quality and quantity in education, is unsatisfactory. Thus, by the beginning of 2016, out of 4671,6 thousand employed population of Azerbaijan,16.3\% received completed high education degree, $10.6 \%$ - high education, $5.5 \%$ - vocational, $60.4 \%$ - secondary, $6.3 \%$ - general secondary, and $0.9 \%$ - primary education. At the same time, out of 243.7 thousand unemployed population, $15.4 \%$ received completed high education degree, $12.9 \%$-high education, $4.1 \%$-vocational, $53.3 \%$ - secondary, $13.6 \%$ - general secondary, and $0.7 \%$ - primary education. One of the main reasons for unemployment is that people are unable to find jobs matching their qualifications or have no opportunity to re-study to work in vacant workplaces $[37,38]$. 
Evidently, the universities in Azerbaijan are located either in the capital or in the regional centers. On the other hand, the citizens who had no chance to be a student in the first year of the graduation usually do not either have the desire to study after the military service or other concerns are more prevalent, i.e., frequently updated technology requires knowledge renewal. Therefore, people need to temporarily move to other places because of their work, and the emerging market economy requires more knowledge to produce more competitive products. All these are possible only by remote education, and the remote education is only electronic or virtual universities. The electronic university is an essential requirement of the information society.

It should be noted, unfortunately, the introduction of electronic education is not yet a priority of the Republic of Azerbaijan, and the term "e-education" is not reflected in the relevant regulations. As a result, there are a few examples and research in this field. Certain measures have been taken in this field only at several universities of Azerbaijan, for example,e-university projects by KOICA at the Nakhchivan State University and Azerbaijan Technical University. However, the e-university models built within this project do not fully comply with the features of the Azerbaijani education system. For example, although Nakhchivan State University has established e-exam, e-journal, e-student registration and mobility systems in line with the Azerbaijani education system, these modules do not fully cover the perfect e-university model that provides for the educational needs of the above listed categories of the population.

The comparison of the existing models shows that none of them fully corresponds to the education legislation of Azerbaijan and the requirements of the general public. Therefore, the transition to a bimodal university model providing Blended Learning is more appropriate for the Azerbaijani educational environment. This educational model involves the use of traditional elearning as well as the use of remote e-learning, in other words, it combines both forms of education in the general curriculum. The blended educational model has been accepted as a superior model by many educational institutions. This is also confirmed by the results of a survey conducted by the European Association of Universities in 2013 on the use of electronic technologies in education. The survey was conducted with 38 European educational institutions (249 universities from 38 European countries, i.e., 1/3 of the total European Higher Education), and addressed the three main questions: what kind of electronic education do they use? How do they use? What are their expectations? The results of the survey show that almost all European universities use the electronic educational technologies in their activities. In this case, $91 \%$ of the surveyed enterprises used the blended educational model, in other words, the learning process and practice could be conducted both within the building walls and at home. Whereas, $82 \%$ of the surveyed universities offered online courses; while, $75 \%$ of the respondents admitted that e-education had changed the approach to the process of learning and teaching, and finally, $87 \%$ of the respondents saw the e-learning as the catalysts for future changes in teaching methods [39]. When analyzing the problem from the other point of view, it seems that a direct transition to a virtual university model has not been realized yet in any advanced countries. It is believed that the blended electron university model can meet the requests of the population in need of education that can non-traditionally receive a full-quality education.

Accordingly, we offer the e-learning model for the educational environment in Azerbaijan provided in Figure 5. E-universities in Azerbaijan can be built at the expense of the citizens of the following categories, and the student potential can be formed:

- graduates of the small towns, settlements and rural schools with no opportunity to study in the center;

- the employees of the regional companies, enterprises and organizations;

- the soldiers and officers at the army;

- the employees dismissed from the special service agencies;

- the citizens wishing to pursue the second qualification or upgrading;

- the people temporarily deprived of liberty; 
- the people with disabled people;

- the citizens of Turkic-speaking countries;

- the foreign citizens by preparing educational materials in foreign languages.

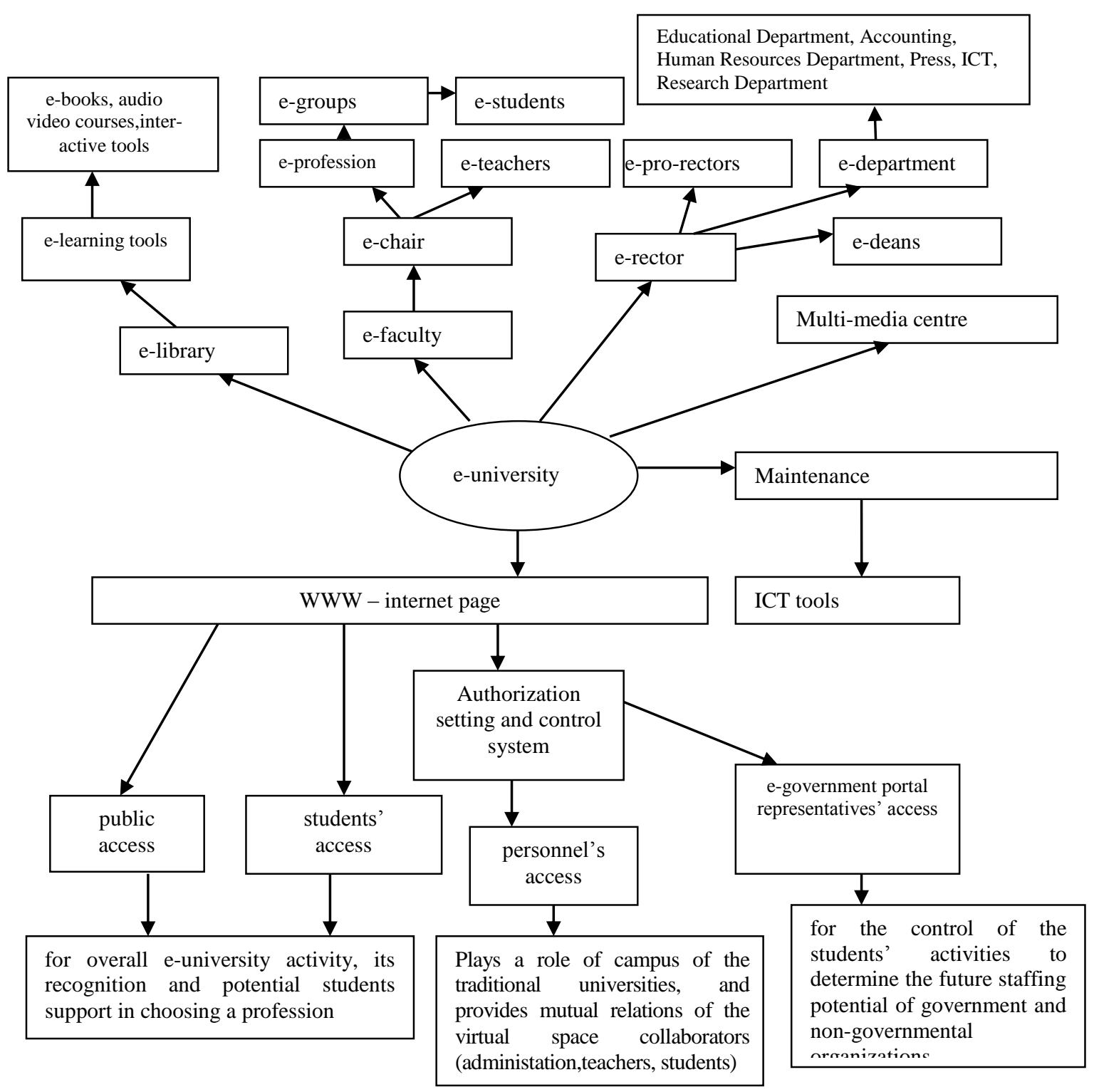

Figure 5. The structural model of e-university proposed for the Azerbaijani educational environment

\section{Conclusion}

The current state of the science and education, based on economic factors, is characterized by the increase of the requirements for the training of specialists and their availability rate. This identifies the constant search for new methods and tools to increase the efficiency of the teaching process. The issue of improving the quality of education can be addressed through the use of ICT. This approach will provide the opportunities for modernizing the education content, expanding the access to education, transferring the teaching sessions from traditional audiences to virtual ones and ensuring their flexibility, enhancing the learners' independent work and optimizing the teaching process. In order to realize the concept of the application of distant technologies in education, it is important to make global changes in the education system as a whole and, first of all, the classic university model should be changed into the electronic university model. 
In the globalizing world, the emergence of e-universities and the introduction of e-learning in Azerbaijan is an inevitable process in the light of the development of new technologies. This requires managing the teaching process by modern methods, building educator-learner relationships on new principles, developing new teaching contents in line with the expectations of the consumers of teaching services, and ensuring the access to education for different categories of the population. The issues listed above should be resolved to accelerate the e-education process and e-universities as its implementing structure in the country. This is related to the change of the public opinion and mentality as well as the adaptation of the technological and legal-normative base of education to the new realities.

\section{References}

1. www.unesco.org/new/en/education/themes/leading-the-internat.../education-for-all/

2. Mammadova M.G., Ok N.I. The current state of continuous professional training in Azerbaijan // Labor market and employment, Kiev, No4 (33), 2012, pp.15-21. www.ipkdszu.kiev.ua

3. Lifelong learning.http://infed.org/mobi/lifelong-learning/

4. Mikheeva SA, Svit E.P. Experience and perspectives of the use of e-learning in the educational environment of the Pedagogical University // News of the Russian State Pedagogical University. A.I. Herzen, vol.No 168, 2014, pp.122-127.

5. Challenges and Disadvantages of E-learning and Distance Learning, 2009, http://compassioninpolitics.wordpress.com/2009/09/26/

6. Amanda A. Reece. Best practices in digital object development for education: Promoting excellence and innovation in instructional quality and assessment // Journal of Learning Design, 2016, vol.9, no.1, pp.80-86.

7. MacNeill S., Johnston B. The Digital University in the Modern Age: A proposed framework for strategic development // Compass: Journal of Learning and Teaching, 2013, vol.4, no.7. https://journals.gre.ac.uk/index.php/compass/article/view/79/0

8. Siemens G., Gashevich D., Dawson S. Preparing for the digital university: a review of the history and current state of distance, blended, and online learning. 2015, 234 p. http://linkresearchlab.org/PreparingDigitalUniversity.pdf

9. MacNeill, S. and Johnson, B. What is nature of distribution in the digital age? // Journal of Perspectives in Applied Academic Practice, 2015, vol.3, Issue 1, pp.3-5.

10. Tapscott, D., and A. Williams. 2010. Innovating the 21 st century university: It's time. EDUCAUSE Review 45 (1):16-29.

11. Jones $C$. The digital university: A concept in need of a definition. In Literacy in the digital university - Critical perspectives on learning, scholarship and technology, ed. R. Good fellow and M. Lea, London: Routledge, 2013, 162-172.

12. The "Digital University": Discourse, Theory, and Evidence // The International Journal of Learning and Media, 2012, vol. 4, no.3-4, pp.59-63.www.mitpressjournals.orgdoi/pdf/ 10.1162/IJLM)

13. Elif Yüksel Oknay. Türkiye'de Uzaktan Eğitim Ve Çalışma Hayatı / International Distance Education Conference 2015 - September 2-4, 2015, St. Petersburg, Rusia, pp. 448-464.

14. Tracey M., \& Richey R. The evolution of distance education. Distance Learning, 2005, 2(6), $17-21$.

15. The IBM Global Campus (http://ike.engr.washington.edu/igc/)

16. The Minnesota Initiative (www.ot.state.mn.us/)

17. Distance educational technologies: projection and implementation of training courses / Under the general. Ed. M. B. Lebedeva, St. Petersburg .: BHV-Petersburg, 2010, 336 p.

18. Real Education (www.realeducation.com/)

19. www.studygs.net/online/The online learning series.html 
20. http://online.uophx.edu

21. Learning Technology Products 2009. Authoring Tools, Learning Management Systems, and Learning Content Management Systems / Brandon Hall Research — Sunnyvale, CA, March 2009. 77. Providing Technological Support to the Swiss Virtual Campus. www.edutech.ch.

22. www-tec.open.ac.uk/systems/st.html

23. Jelonek D., Nowick A., and Ziora L. The Application of e-Learning in the Didactic Process at the Faculty of Management in Czestochowa University of Technology. Organization. Tools. Model / Proceedings of Informing Science \& IT Education Conference (InSITE), 2014, pp.143-156. http://proceedings.informingscience.org/InSITE2014.pdf

24. Al-Taie N. The Effect of Using E-Learning Curriculum And Traditional Classroom Curriculum: Comparison \&Merits / Proceedings of the 6th International Conference on Information Technology (ICIT), 2013, pp.125-134. http://icit.zuj.edu.jo/icit13/index.html.

25. Jelonek D. The Development of Software Agents in e-Learning 3.0 / Proceedings of the 7th International Conference on Information Technology (ICIT), 2015, pp.332-340. http://icit.zuj.edu.jo/ICIT15/index.html

26. Huang S.L., Shiu J.H. A User-Centric Adaptive Learning System for E-Learning 2.0 // Educational Technology \& Society, 2012, 15(3), pp.214-225.

27. Schulmeister R. Students, Internet, eLearning and Web 2.0. In Looking toward the future of technology - enhanced education: Ubiquitous learning and digital native, ed. M. Ebner and M. Schiefner, Hershey, PA: IGI Global, 2010, pp.13-36.

28. Aleshkevich V.A., Klimenko E.V., Sugornaeva S.P. Intellectual web-technologies in education.https://www.scienceforum.ru/2014/pdf/5796.pdf

29. O'Reilly T. Today's Web 3/0 Nonsense Blogstorm. http://radar.oreilly.com/web3-0.html

30. Soon-Hwa K., Ki-SSang S., Se-Young P. Exploring the Technological Factors in SMART Learning Affecting Creativity, Advances in Educational Technologies / Proceedings of the InternationalConference on Education and Modern Educational Technologies (EMET), Greece, 2014, pp.161-166.

31. Sivakumar N., Vivekanandan K., Arthi B., Sandhya S., Katta V., Incorporating Agent Technology for Enhancing the Effectiveness of E-learning System // IJCSI International Journal of Computer Science, 2011, Issue 3, vol.8 (Online): 1694-0814, www.IJCSI.org 4.

32. Jelonek D., Chluski A. The role of software agents in distance education // Business Informatics, 2011, no.17, pp.86-93.

33. https://6bells.wordpress.com/2011/01/09/defining-distance-learning

34. Jennifer Tricoli. Best Practice Guide Converting to a Hybrid Course https://jennifertricoli.wordpress.com/2011/10/23/

35. Defining Distance Learning. https://6bells.wordpress.com/2011/01/09/def-distance-learning/

36. Meiting Bai. The Rural Distance Education in Primary and Secondary Schools in Gansu. www.itdl.org/Journal/jul_08/article02.htm

37. Labor market. Statistical bulletin, 2016. www.stat.gov.az

38. Mammadova M., Mammadzadeh F. Formation of supply and demand for IT Specialists on the base of competency model / IV International Conference "Problems of Cybernetics and Informatics" (PCI-2012), Vol.IV, sept.12-14, 2012, Baku. pp.199-201

39. Research: E-learning in universities in Europe. https://newtonew.com/tech/ 